\title{
Executive functions in children with dyslexia
}

\author{
Funções executivas em crianças com dislexia \\ Thais BARBOSA', Camila Cruz RODRIGUES',2, Claudia Berlim de MELLO', Mariana Cristina de Souza e \\ SILVA', Orlando Francisco Amodeo BUENO'
}

\begin{abstract}
This study aimed to verify whether children with dyslexia have difficulties in executive functions (shifting, working memory, inhibition). Methods: A sample of 47 children (ages 8-13 years) participated in the study: 24 who were dyslexic and 23 controls with typical development. A battery of neuropsychological tests was used. Results: Results revealed executive function difficulties among the dyslexic children when compared with controls, encompassing selective attention modulation processes, shifting, and inhibitory control. These difficulties appeared to be affected by phonological working memory deficits, typically associated with dyslexia. Conclusion: Our findings support the consensus among scholars regarding the central involvement of phonological skill dysfunctions in dyslexia.
\end{abstract}

Keywords: Dyslexia; executive function; child; cognition.

\section{RESUMO}

O objetivo deste estudo foi verificar se crianças com dislexia têm dificuldades nas habilidades de funções executivas (shifting, memória operacional e inibição). Métodos: Uma amostra de 47 crianças (idades entre 8 e 13 anos) participaram do estudo: 24 crianças disléxicas e 23 crianças com desenvolvimento típico. Uma bateria de avaliação neuropsicológica foi usada. Results: Os resultados revelaram dificuldades nas funções executivas nas crianças disléxicas quando comparadas com as controle, envolvendo processos de modulação de atenção seletiva, shifting e controle inibitório. Essas dificuldades parecem ser afetadas pelos déficits na memória operacional fonológica, tipicamente associada à dislexia. Conclusion: Assim, nossos achados suportam o consenso de que a disfunção central da dislexia está nas habilidades fonológicas.

Palavras-chave: Dislexia; função executiva; criança; cognição.

Executive function is defined as a group of mental abilities that allow individuals to engage in socially-adapted and targeted behaviors, as well as to respond to new situations in an adaptive manner, with proper conscious control ${ }^{1}$. It is an umbrella term that involves multiple high-order cognitive

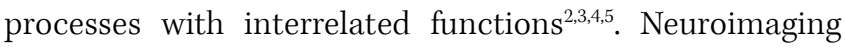
studies corroborate this concept, systematically demonstrating the involvement of a frontal-parietal network in modulating functionally distinct processes ${ }^{5}$. Furthermore, executive functions have also been deemed to be associated with three domains in particular: shifting, working memory, and automatic response inhibition ${ }^{5,6,7}$. According to $\mathrm{Cragg}^{3}$, these functions jointly support the goal-oriented planning capacity.
The presence of executive function disabilities in developmental disabilities are well known, as has been extensively described, especially in attention deficit hyperactivity disorder and autism ${ }^{8,9,10}$. Regarding dyslexia, most studies focus mainly on the influence of working memory disabilities, specifically the phonological working memory, frequently identified as one of the key dysfunctions in this disorder ${ }^{11,12,13,14,15}$.

Scientific evidence, however, indicates that dyslexia may be associated with a broader dysexecutive functioning. A meta-analysis study ${ }^{16}$ established that dyslexic individuals have global executive function difficulties when compared with individuals with good reading skills. It was also reported that differences between groups often varied according to the type of tasks adopted in the assessment procedures. In this

\footnotetext{
'Universidade Federal do Estado de São Paulo, Departamento de Psicobiologia, São Paulo SP, Brasil;

${ }^{2}$ Universidade Presbiteriana Mackenzie, Departamento de Psicologia, São Paulo SP, Brasil.

Thais Barbosa (iD) http://orcid.org/0000-0002-7677-3312; Camila Cruz Rodrigues iD https://orcid.org/0000-0003-4116-9569; Claudia Berlim de Mello (iD https://orcid.org/0000-0003-3953-3966; Mariana Cristina de Souza e Silva iD https://orcid.org/0000-0003-2469-2024; Orlando Francisco Amodeo Bueno iD https://orcid.org/0000-0003-0737-3945

Correspondence: Thais Barbosa; Departamento de Psicobiologia - UNIFESP; Rua Embaú, 54 - Vila Clementino; 04039 -060 São Paulo SP, Brasil; E-mail: barbosa_thais@hotmail.com

Support: This study was supported by Associação Fundo de Incentivo à Pesquisa-AFIP.

Conflict of interest: There is no conflict of interest to declare.

Received 25 June 2018; Received in final form 07 December 2018; Accepted 10 January 2019.
} 
regard, the study emphasized the importance of a more diversified use of quantitative and qualitative procedures to assess executive functions in clinical groups, particularly in dyslexic patients.

The Wisconsin Card Sorting Test (WCST) a neuropsychological test that allows assessment of mental flexibility and inhibitory control skills, has been adopted in dyslexia studies, among other standard executive function measures. In this procedure, participants are asked to identify different categorical criteria for the association of cards, following verbal feedback. In one study ${ }^{17}$, it was observed that dyslexic children identified a smaller number of categories compared with control groups, in addition to showing greater attentional engagement difficulties. These findings suggest problems in shifting, inhibition, and self-monitoring skills. In another study ${ }^{18}$, when compared with children fluent in reading, dyslexic children required more cards to complete a category, completed fewer categories and made more errors, which relates to shifting difficulties. A study published with Brazilian Portuguese speakers illustrated the difference between dyslexic children and controls regarding the number of categories completed and the number of cards used in the WCST; the dyslexic children completed a smaller number of categories and required a higher number of cards to complete the task, potentially indicating mental flexibility and problem-solving impairments ${ }^{19}$.

A performance evaluation of children with and without dyslexia in the Conners' Continuous Performance Test (CCPT) showed that dyslexic children had more flaws in inhibitory control (commission errors), higher response variability, more perseverative errors, and lower response consistency over time. These results point to difficulties regarding inhibitory control, including impulsivity, and sustained attention problems ${ }^{20}$.

More recently, deficits were identified in several executive function domains in dyslexic children, such as verbal fluency, attention, and phonological working memory, in addition to those commonly found in phonological awareness tasks ${ }^{21}$. In turn, difficulties were identified in verbal fluency and shifting among Portuguese children with dyslexia ${ }^{4}$.

On the other hand, some studies failed to reach consistent results regarding the presence of broad executive function disabilities in reading and writing disorders. Dyslexic individuals were submitted to executive functioning skills (inhibition, working memory and attention), phonological skills, and time perception measures. The results showed impairments only in phonological skill measures ${ }^{22}$.

In a study conducted with Brazilian Portuguese speakers, children aged six to eight, referred by their teachers as good or poor readers at the beginning of the literacy teaching process, were compared for selective attention, inhibition, flexibility, and working memory skills tests. Only working memory and flexibility impairments were directly related to reading difficulties ${ }^{23}$.
Therefore, considering the controversy surrounding the involvement of broad executive function disorders in dyslexia, the purpose of this study was to ascertain whether dyslexic children have difficulties in executive function and in which of its key processes they occur: shifting, working memory and response inhibition.

\section{METHODS}

\section{Participants}

A sample of 47 children between the ages of eight and 13 participated in the study: 24 dyslexic children (dyslexia group - DG) with no comorbidities; and 23 children with typical development (control group - CG), paired by age, sex and school attendance (private or public school).

Participants of the DG were selected from a sample of 110 children assessed at a learning disabilities outpatient clinic in Brazil (Núcleo de Atendimento Neuropsicológico Infantil Interdisciplinar). Participants from the CG were assessed at their schools, and were required to show adequate academic performance based on the respective school grade and age. The period of recruitment extended from 2014 to 2015. All the children were submitted to a broad neuropsychological battery comprising tests and tasks involving oral language, reading and writing, in individual sessions of approximately one hour each. The dyslexia diagnosis was based on the following instruments: CONFIAS - the Phonological Awareness, Instrument of Sequential Assessment; the TDE School Performance Test; reading and writing of words and pseudowords; reading silently and reading aloud task; and a reading comprehension task (see Cruz-Rodrigues et al. ${ }^{19}$ and Barbosa et al. ${ }^{24}$ for further explanations about these tests).

The dyslexic children were previously diagnosed based on the following criteria, as established in the DSM-5: persistent reading and writing difficulties from the beginning of the literacy teaching process; selective deficits in reading and writing accuracy; and slow reading. All the children of the CG had good academic performance and attended public or private schools.

Neither group included children with an intellectual performance below 90, as assessed by the Wechsler Intelligence Scale, sensory or motor disabilities, or a history of psychiatric/neurological comorbidities such as attention deficit hyperactivity disorder, or anxiety disorder as evaluated by the Brazilian version of the Child Behavioral Checklist and SNAP-IV Parent Rating Scale. This information was obtained from the respective parents or legal guardians, who signed an informed consent form authorizing the children's participation in the study, which was approved by CEP/UNIFESP.

\section{Procedures}

The battery used for the assessment of executive function included the following tests: 


\section{Attention and Inhibition}

Conners' Continuous Performance Test - software for Windows (CCPT 4$)^{25}$ - presented on a laptop, covering an application time of approximately 20 minutes, including training and testing activities. Participants are required to press the keyboard space bar when any letter appears on the screen, except for "X". Each letter is shown for approximately 250 milliseconds. There are 324 target stimuli and 36 non-target stimuli ("X" letters). Six stimuli blocks are shown, each with three sub-blocks of 20 items each (letters shown) and interstimulus intervals of one, two and four seconds ${ }^{26,27}$.

\section{Phonological Working Memory}

Digit Span (WISC-III ${ }^{28}$ ), forward and backward order. In this classic phonological working memory task, the examiner reads progressively larger number sequences aloud (up to eight numbers). For each forward order sequence, the child repeats the numbers in the same order they were given. For each backward order sequence, the child repeats the numbers in reverse order. Each item has two attempts, with different numbers, and each attempt has the same number of $\operatorname{digits}^{28}$. The final score represents all numbers correctly repeated in sequence (forward and backward).

Brazilian Children's Test of Pseudoword Repetition ${ }^{29}$. The task comprises 40 pseudowords. The examiner places a blindfold on the children to prevent them from identifying any facial queues and asks them to repeat pseudowords exactly as they were heard. One point is given for each correct answer. This task assesses phonological working memory.

\section{Visuospatial Working Memory}

Corsi Block-tapping test - forward and backward order ${ }^{30}$. This test comprises nine blue blocks irregularly arranged over a white board. During the task, the examiner taps predefined and progressively longer block sequences, and the participant must repeat the movements in the same sequence. In the backward test, the participant is required to repeat the block-tapping sequences in reverse order. There are two attempts for each sequence. The test is interrupted when the participant makes two consecutive mistakes or completes the nine-digit sequence.

\section{Shifting}

Wisconsin Card Sorting Test - manual version. This test consists of a set of 128 stimulus cards with different patterns on white backgrounds, as well as four target cards placed in front of the participant, featuring assorted attributes (shape, number, and color). The target cards, in order of presentation, are: one red triangle, two green stars, three yellow crosses, and four blue circles. The participants are required to match the cards from the set with the target cards, one at a time, based on the respective attributes. There is a predefined matching sequence (color, shape, quantity), which is not revealed to the participants. In other words, the strategy initially required from the participants is to match cards based on color. After correctly matching ten cards, they must then match cards based on the shape. After ten cards are matched, they must then match cards based on the quantity, and so on successively until all six categories are completed. The examiner informs the participants whether the adopted strategy is correct or incorrect ${ }^{31,32}$.

\section{Statistical analysis}

The statistical analysis was performed using the SPSS statistical package - Version 18. The level of significance adopted was $5 \%$. The Chi-square test was performed for string variables. Levene's test was initially performed for numeric variables, in order to analyze distribution. Since the variables had normal distribution, the Student's t-test was performed. However, we identified inconsistencies in the level of intelligence of children between the DG and CG, which was higher in the latter. Therefore, we performed the Analysis of Covariance (ANCOVA) for significant variables in the Student's t-test.

\section{RESULTS}

The sample characterization is described in Table 1. The distribution of groups based on age, sex, and school type was not divergent due to the pairing strategy adopted.

In the CCPT (Table 2), the measures that showed disparities were the number of omissions $(\mathrm{p}=0.01)$ and percentage of omissions $(p=0.02)$, which were higher in the DG compared with the CG; and the reaction time (Hit RT) $(p=0.001)$, in which the DG was significantly slower than the CG (more time).

Regarding working memory, the DG underperformed in the Brazilian Children's Test of Pseudoword Repetition test for five-syllable items $(p=0.0005)$ and the backward Digit Span test ( $p=0.007$ ). No differences were observed between both groups in the Corsi Block-tapping test (Table 3).

In the WCST (Table 4), the DG underperformed only in the percentage of perseverative errors $(\mathrm{p}=0.04)$. It is important to note that other WCST variables with significant

Table 1. Sociodemographic characterization if dyslexic and controls groups.

\begin{tabular}{lcc}
\hline Variable & Dyslexic group & Control group \\
\hline Age (Average) & $11( \pm 1.7)$ & $10.9( \pm 1.8)$ \\
Sex & 18 male & 16 male \\
& 6 female & 7 female \\
School Type & 15 public school & 15 public school \\
& 9 private school & 8 private school \\
\hline
\end{tabular}


Table 2. Differences in Connors' Continuous Performance Test (CCPT) measures between the dyslexia group and the control group.

\begin{tabular}{|c|c|c|c|}
\hline ССРT Measures & Dyslexic group & Control group & $p$-value \\
\hline Gross omissions* & $21.3( \pm 14.4)$ & $8.7( \pm 9.8)$ & 0.01 \\
\hline Percentage of omissions* & $6.2( \pm 4.7)$ & $2.7( \pm 3)$ & 0.02 \\
\hline Gross commissions* & $22( \pm 8.1)$ & $19.6( \pm 8.5)$ & 0.4 \\
\hline Percentage of commissions & $61.1( \pm 22.6)$ & $54.7( \pm 23.8)$ & 0.4 \\
\hline Hit RT* & $477.7( \pm 88.1)$ & $389.4( \pm 70.8)$ & 0.001 \\
\hline Hit RT SE & $15.6( \pm 6.6)$ & $8.9( \pm 4.1)$ & 0.2 \\
\hline Variability & $35( \pm 21)$ & $20( \pm 16.7)$ & 0.06 \\
\hline Detectability $\left(d^{\prime}\right)$ & $0.4( \pm 0.4)$ & $0.5( \pm 0.4)$ & 0.5 \\
\hline Response Style (b) & $1.5( \pm 2)$ & $1.4( \pm 2.3)$ & 0.9 \\
\hline Perseverations & $12.7( \pm 15.7)$ & $3.2( \pm 6.8)$ & 0.06 \\
\hline Hit RT block change & $0.03( \pm 0.06)$ & $0.01( \pm 0.03)$ & 0.2 \\
\hline Hit SE block change & $0.13( \pm 0.1)$ & $0.08( \pm 0.1)$ & 0.2 \\
\hline Hit RT ISI change & $0.1( \pm 0.07)$ & $0.07( \pm 0.06)$ & 0.3 \\
\hline Hit SE ISI change & $0.2( \pm 0.2)$ & $0.1( \pm 0.2)$ & 0.2 \\
\hline
\end{tabular}

*Control group outperformed dyslexic group; ISI: Inter-Stimulus Interval; Hit RT: Hit Reaction Time; Hit RT SE: Hit Reaction Time Standard Error.

Table 3. Differences in working memory measures between the dyslexia group and the control group.

\begin{tabular}{|c|c|c|c|c|}
\hline Measures & & Dyslexic group & Control group & $\mathrm{p}$-value \\
\hline \multicolumn{5}{|c|}{ Phonological working memory } \\
\hline \multirow{4}{*}{ BCPR } & 2 syllables & $9.8( \pm 0.4)$ & $10( \pm 0.2)$ & 0.08 \\
\hline & 3 syllables & $9.3( \pm 0.6)$ & $9.7( \pm 0.6)$ & 0.06 \\
\hline & 4 syllables & $8.8( \pm 1)$ & $9.5( \pm 0.5)$ & 0.6 \\
\hline & 5 syllables* & $6.8( \pm 2.2)$ & $9.5( \pm 0.8)$ & 0.0005 \\
\hline \multicolumn{5}{|c|}{ Visuospatial working memory } \\
\hline \multirow{2}{*}{ Digit span } & Forward & $4( \pm 0.6)$ & $5.1( \pm 1.1)$ & 0.1 \\
\hline & Backward* & $2.8( \pm 0.7)$ & $4.1( \pm 1)$ & 0.007 \\
\hline \multirow{2}{*}{ Corsi block-tapping test } & Forward & $4.8( \pm 1.3)$ & $5.5( \pm 1)$ & 0.6 \\
\hline & Backward & $4.3( \pm 1.1)$ & $4.9( \pm 1.1)$ & 0.06 \\
\hline
\end{tabular}

*Control group outperformed dyslexic group; BCPR: Brazilian Children's Test of Pseudoword Repetition.

Table 4. Differences in the Wisconsin card sorting test measures between the dyslexia group and the control group.

\begin{tabular}{lccc}
\hline Measures & Dyslexic group & Control group & p-value \\
\hline Total cards & $116.1( \pm 19.5)$ & $102.8( \pm 19.8)$ & 0.3 \\
Correct answers & $71( \pm 13)$ & $73.2( \pm 13)$ & 0.6 \\
Percentage of errors & $36.4( \pm 15.3)$ & $26.4( \pm 14.6)$ & 0.06 \\
Percentage of perseverative answers & $24.3( \pm 17.6)$ & $11.9( \pm 6.6)$ & 0.6 \\
Percentage of perseverative errors* & $20.4( \pm 13.3)$ & $11.1( \pm 6.2)$ & 0.04 \\
Percentage of non-perseverative errors & $15.8( \pm 9.8)$ & $14.8( \pm 9.1)$ & 0.7 \\
Number of categories completed & $4.4( \pm 1.6)$ & $5.3( \pm 1.5)$ & 0.07 \\
Failure to maintain setting & $0.9( \pm 1.1)$ & $1( \pm 1.2)$ & 0.9 \\
\hline
\end{tabular}

*Control group outperformed dyslexic group.

differences were identified prior to the analysis of covariance based on the level of intelligence (total number of tests, number of categories completed, percentage of errors and percentage of perseverative answers), all of which showed a lower performance in the DG. These findings indicate that this test is significantly influenced by the level of intelligence. 


\section{DISCUSSION}

The results obtained in this study indicated significant discrepancies in the performance of the dyslexic children surveyed in some of the executive function measures, in comparison with children with typical development, thus reinforcing current evidence that reading and writing disabilities are at least partly associated with executive function disabilities.

Regarding the inhibition domain, as inferred by the CCPT test results, a slow motor response and a tendency towards omission-type errors were identified, whereas no impulsive response inhibition difficulties were encountered, although other studies had identified inhibitory control (impulsivity) and sustained attention difficulties in their studied sample ${ }^{20}$. Another study based on CCPT applied to dyslexic children did not reveal any differences in surveyed measures, when compared with the control group ${ }^{30}$. Therefore, our results seem to support the notion that despite not being clinically diagnosed with attention deficit/hyperactivity disorder, dyslexic children tend to show difficulties in modulating attention, rather than inhibitory control disabilities ${ }^{18}$.

Regarding the working memory domain, as expected, phonological working memory specifically appeared to be the most fragile cognitive area among the participants. In fact, no significant differences were identified between the children in the DG and the CG in nonverbal working memory measures (assessed via the Corsi Block-tapping test). This result indicates that dyslexia is not associated with global working memory losses, but rather with specific deficits in the processing of verbal materials (phonological working memory), which has been described in several studies $^{11,12,13}$. Furthermore, the ability to retain phonological working memory was also affected, as assessed via the Brazilian Children's Test of Pseudoword Repetition test that indicated difficulties centered in phonological skills, rather than in working memory manipulation skills, which would be more intimately related to executive functions.

A study by Engel et al. ${ }^{33}$ confirmed that working memory measures were not influenced by the environmental variables of studied children, as opposed to analyses regarding the level of verbal intelligence ${ }^{33}$. Therefore, it is possible to infer, that although working memory and intelligence are intimately related, working memory performance is a better indicator of a child's learning potential than intelligence measures, which mainly assess prior knowledge acquired at home and at school. Working memory measures are, therefore, seen as far more useful procedures for learning disabilities diagnostic processes.

Finally, considering the results of the WCST, a higher percentage of perseverative errors were recorded in children of the DG, compared with the CG, suggesting that shifting and inhibition abilities may be compromised in dyslexic patients ${ }^{17}$. No differences regarding the number of identified categories were encountered, as opposed to other findings ${ }^{19}$.

On the other hand, problems in the phonological working memory may also potentially explain the increased number of perseverative errors within the DG. That is, although the WCST is traditionally used as a shifting measure, it is a complex task that also requires phonological working memory abilities to maintain the current memory category until the task is completed. In fact, recurring evidence indicates that phonological working memory deficits are associated with a higher frequency of perseverative errors in the WCST $\mathrm{W}^{6,34,35}$. These deficits supposedly affect the permanence of the current category in the memory and the benefit of the examiner's feedback, leading the child to commit more errors of this type ${ }^{3}$. Therefore, despite some authors employing the WCST in children with learning disabilities due to its nonverbal nature, this does not mean that the test does not involve verbal skills, such as the phonological working memory ${ }^{16,18}$.

In summary, this study observed executive function difficulties among dyslexic children, encompassing selective attention modulation processes (translated into slower responses and a tendency towards omission errors in the CCPT), as well as shifting and inhibitory control (frequency of perseverative errors in the WCST), which seemed to be affected by phonological working memory deficits, typically associated with this diagnosis. Limitations of the study include the small sample size and the use of some instruments not fully adapted for the Brazilian population, although we used a control group for comparison. Nevertheless, our findings support the general consensus among scholars regarding the central involvement of phonological working memory alterations in dyslexia, which better explain the inherent difficulties with executive functions in this diagnosis. Further research on this matter is required, primarily to assess the influence of phonological working memory on executive functions.

\section{References}

1. Lezak MD, Howieson DB, Loring DW. Neuropsychological Assessment. 5th ed. New York: Oxford University Press; 2012.

2.

Weyandt LL. Executive function in children, adolescents, and adults with attention deficit hyperactivity disorder: introduction to the special issue. Dev Neuropsychol. 2005;27(1):1-10. https://doi.org/10.1207/s15326942dn2701_1

3. Cragg L. The development of executive function in childhood [thesis] Oxford: St John's College, University of Oxford; 2007.
4. Moura O, Simões MR, Pereira M. Executive functioning in children with developmental dyslexia. Clin Neuropsychol. 2015;28(sup 1):s20-41. https://doi.org/10.1080/13854046.2014.964326

5. Friedman NP, Miyake A. Unity and diversity of executive functions: individual differences as a window on cognitive structure. Cortex. 2017 Jan;86:186-204. https://doi.org/10.1016/j.cortex.2016.04.023

6. Miyake A, Friedman NP, Emerson MJ, Witzki AH, Howerter A, Wager TD. The unity and diversity of executive functions and 
their contributions to complex "Frontal Lobe" tasks: a latent variable analysis. Cognit Psychol. 2000 Aug;41(1):49-100. https://doi.org/10.1006/cogp.1999.0734

7. Best JR, Miller PH. A developmental perspective on executive function. Child Dev. 2010 Nov-Dec;81(6):1641-60. https://doi.org/10.1111/j.1467-8624.2010.01499.x

8. Capovilla AG, Assef EC, Cozza HF. Avaliação neuropsicológica das funções executivas e relação com desatenção e hiperatividade. Aval Psicol. 2007;6:51-60

9. Narzisi A, Muratori F, Calderoni S, Fabbro F, Urgesi C. Neuropsychological profile in high functioning autism spectrum disorders. J Autism Dev Disord. 2013 Aug;43(8):1895-909. https://doi.org/10.1007/s10803-012-1736-0

10. Sroubek A, Kelly M, Li X. Inattentiveness in attention-deficit/ hyperactivity disorder. Neurosci Bull. 2013 Feb;29(1):103-10. https://doi.org/10.1007/s12264-012-1295-6

11. Ramus F, Rosen S, Dakin SC, Day BL, Castellote JM, White S, et al. Theories of developmental dyslexia: insights from a multiple case study of dyslexic adults. Brain. 2003 Apr;126(Pt 4):841-65. https://doi.org/10.1093/brain/awg076

12. Fletcher JM. Dyslexia: the evolution of a scientific concept. J Int Neuropsychol Soc. 2009 Jul;15(4):501-8. https://doi.org/10.1017/S1355617709090900

13. Hulme C, Snowling MJ. The interface between spoken and written language: developmental disorders. Philos Trans R Soc Lond B Biol Sci. 2013 Dec;369(1634):20120395. https://doi.org/10.1098/rstb.2012.0395

14. Hulme C, Snowling MJ. Developmental disorders of language, learning and cognition. Oxford: Wiltry-Blackwell; 2009.

15. Peterson RL, Pennington BF. Developmental dyslexia. Annu Rev Clin Psychol. 2015;11(1):283-307. https://doi.org/10.1146/annurev-clinpsy-032814-112842

16. Booth JN, Boyle JM, Kelly SW. Do tasks make a difference? Accounting for heterogeneity of performance of children with reading difficulties on tasks of executive function: findings from a meta-analysis. Br J Dev Psychol. 2010 Mar;28(Pt 1):133-76. https://doi.org/10.1348/026151009X485432

17. Menghini D, Finzi A, Benassi M, Bolzani R, Facoetti A, Giovagnoli S, et al. Different underlying neurocognitive deficits in developmental dyslexia: a comparative study. Neuropsychologia. 2010 Mar;48(4):863-72. https://doi.org/10.1016/j.neuropsychologia.2009.11.003

18. Helland T, Asbjørnsen A. Executive functions in dyslexia. Child Neuropsychol. 2000 Mar;6(1):37-48. https://doi.org/10.1076/0929-7049(200003)6:1;1-B;FT037

19. Cruz-Rodrigues C, Barbosa T, Toledo-Piza CM, Miranda MC, Bueno OF. Neuropsychological characteristics of dyslexic children. Psicol Reflex Crit. 2014;27(3):433-40. https://doi.org/10.1590/1678-7153.201427315

20. Miranda MC, Barbosa T, Muszkat M, Rodrigues CC, Sinnes EG, Coelho LF, et al. Performance patterns in Conners' CPT among children with attention deficit hyperactivity disorder and dyslexia. Arq Neuropsiquiatr. 2012 Feb;70(2):91-6. https://doi.org/10.1590/S0004-282X2012000200004
21. Varvara P, Varuzza C, Sorrentino AC, Vicari S, Menghini D. Executive functions in developmental dyslexia. Front Hum Neurosci. 2014 Mar;8:120. https://doi.org/10.3389/fnhum.2014.00120

22. Gooch D, Snowling M, Hulme C. Time perception, phonological skills and executive function in children with dyslexia and/or ADHD symptoms. J Child Psychol Psychiatry. 2011 Feb;52(2):195-203. https://doi.org/10.1111/j.1469-7610.2010.02312.x

23. Engel de Abreu PM, Abreu N, Nikaedo CC, Puglisi ML, Tourinho CJ, Miranda MC, et al. Executive functioning and reading achievement in school: a study of Brazilian children assessed by their teachers as "poor readers". Front Psychol. 2014 Jun;5:550. https://doi.org/10.3389/fpsyg.2014.00550

24. Barbosa T, Rodrigues CC, Toledo-Piza CM, Navas AL, Bueno OF. Profile of language and cognitive functions in children with dyslexia in speakers of Brazilian Portuguese. CoDAS. 2015 Nov-Dec;27(6):565-74. https://doi.org/10.1590/2317-1782/20152015043

25. Conners CK. Conners' continuous performance test. Toronto: Multi-Health System; 2002.

26. Riccio CA, Reynolds CR, Lowe P, Moore JJ. The continuous performance test: a window on the neural substrates for attention? Arch Clin Neuropsychol. 2002 Apr;17(3):235-72. https://doi.org/10.1093/arclin/17.3.235

27. Miranda MC, Sinnes EG, Pompéia S, Bueno OFA. A comparative study of performance in the Conners' Continuous Performance Test between Brazilian and North American children. J Atten Disord. 2008 Mar;11(5):588-98. https://doi.org/10.1177/1087054707299412

28. Wechsler D. Escala de Inteligência Wechsler para Crianças. 3rd ed. São Paulo: Casa do Psicólogo; 2003

29. Santos FH, Bueno OF. Validation of the Brazilian Children's test of pseudoword repetition in portuguese speakers aged 4 to 10 years. Braz J Med Biol Res. 2003 Nov;36(11):1533-47. https://doi.org/10.1590/S0100-879X2003001100012

30. Santos FH, Mello CB, Bueno OF, Dellatolas G. Cross-cultural differences for three visual memory tasks in Brazilian children. Percept Mot Skills. 2005 Oct;101(2):421-33. https://doi.org/10.2466/pms.101.2.421-433

31. Heaton RK, Chelune GJ, Talley JL, Kay GG, Curtiss G. Teste Wisconsin de classificação de cartas (WCST). São Paulo: Casa do Psicólogo; 1993.

32. Cunha JA, Trentini CM, Argimon IL, Oliveira MS, Werlang BS, Prieb RG. WCST: Manual. São Paulo: Casa do Psicólogo; 2005.

33. Engel PM, Santos FH, Gathercole SE. Are working memory measures free of socioeconomic influence? J Speech Lang Hear Res. 2008 Dec;51(6):1580-7. https://doi.org/10.1044/1092-4388(2008/07-0210)

34. Bujoreanu IS, Willis WG. Developmental and neuropsychological perspectives on the Wisconsin Card Sorting Test in children. Dev Neuropsychol. 2008;33(5):584-600. https://doi.org/10.1080/87565640802254364

35. Horowitz-Kraus T. Pinpointing the deficit in executive functions in adolescents with dyslexia performing the Wisconsin card sorting test: an ERP study. J Learn Disabil. 2014 May-Jun;47(3):208-23. https://doi.org/10.1177/0022219412453084 